\title{
Differential Expression of Two Cell Surface Proteins, Neuropilin and Plexin, in Xenopus Olfactory Axon Subclasses
}

\author{
Masahiko Satoda, ${ }^{a}$ Shin Takagi, Kunimasa Ohta, ${ }^{b}$ Tatsumi Hirata, and Hajime Fujisawa \\ Department of Molecular Biology, School of Science, Nagoya University, Chikusa-ku, Nagoya 464-01, Japan
}

Immunohistochemistry by using monoclonal antibodies named $A 5$ and $B 2$, which specifically recognize cell surface proteins the neuropilin and the plexin, respectively, revealed that olfactory axons in Xenopus tadpoles were classified into several subgroups by virtue of the expression levels of these two cell surface molecules. The vomeronasal axons expressed the plexin but not the neuropilin. The plexin-positive and neuropilin-negative vomeronasal axons form a discrete fiber bundle, even after they joined with the principal olfactory axons. However, the principal olfactory axons were divided into at least two subclasses; the neuropilin-predominant axons which expressed high levels of the neuropilin and low levels of the plexin, and the plexin-predominant axons which expressed high levels of the plexin and low levels of the neuropilin. Within the olfactory nerve the pathways for these two principal olfactory axon subclasses were initially intermingled with each other, but were gradually segregated throughout their courses from the nose to the cerebrum. Eventually, the neuropilin-predominant and the plexin-predominant principal olfactory axon subclasses projected to specified glomeruli in topographically related regions within the main olfactory bulb. Neuroanatomical tracings of the olfactory projection also confirmed the gradual segregation of the pathways for the principal olfactory axons. These results allow us to speculate that both the neuropilin and the plexin are involved in axon interactions, and play roles in the organization of the precise patterns of the olfactory pathway and projection.

[Key words: cell surface molecule, axon fasciculation, pathway organization, olfactory system, Xenopus tadpole, immunohistochemistry]

Navigation of axons along particular routes toward their targets is a critical step to produce precise patterns of neuronal connections. Among several different mechanisms to bring about directional growth of axons, such as diffusible tropic factors, repulsion, contact mediated cues, or mechanical channels (Dodd

\footnotetext{
Received Nov. 22, 1993; revised July 22, 1994; accepted July 25, 1994.

This work was supported by grants from the Ministry of Education, Science and Culture, Japan; a grant from the Mitsubishi Foundation; and a grant from the Uehara Foundation.

Correspondence should be addressed to Hajime Fujisawa, Ph.D., at the above address.

aresent address: Department of Medicine, Kyoto Prefectural University of Medicine, Kamikyo-ku, Kyoto 602, Japan.

b Present address: Division of Developmental Neurobiology, Department of Neuroscience and Immunology, Kumamoto University Graduate School of Medical Sciences, Kuhonji, Kumamoto 862, Japan.

Copyright (C) 1995 Society for Neuroscience $0270-6474 / 95 / 150942-14 \$ 05.00 / 0$
}

and Jessell, 1988; Goodman and Shatz, 1993), axon-axon interactions play a role in preferential guidance of growing axons along specified paths, giving rise to stereotyped patterns of nerve fiber tracts and connections (Bastiani et al., 1984; Goodman et al., 1984; Kuwada, 1986; Chitnis and Kuwada, 1991). Monoclonal antibody screening and genetic analyses have been accumulating information for molecules involved in axon interaction and growth cone navigation in invertebrate nervous systems (Bastiani et al., 1987; Elkins et al., 1990; Grenningloh et al., 1991), but very few in vertebrates.

The olfactory projection in vertebrates seems to provide a unique model system for attempting to analyze cellular and molecular mechanisms underlying the organization of nerve fiber tract and connections, because of the diverse types of olfactory receptors and axons, and because of their spatially ordered projections. The olfactory system in amphibia, as in other vertebrate species, consists of two anatomically and functionally different classes of receptors: the vomeronasal receptors (the vomeronasal system) and the principal olfactory receptors (the principal olfactory system) which project to discrete target regions within the cerebrum. Moreover, recent immunohistochemical approaches on the mammalian olfactory systems have revealed that both the vomeronasal and principal olfactory systems are further divided into several biochemically different receptor subclasses (Allen and Akeson, 1985a,b; Fujita et al., 1985; Imamura et al., 1985; Mori et al., 1985; Key and Giorgi, 1986; Schwob and Gottlieb, 1986, 1988; Mori, 1987; Mori et al., 1987; Onoda and Fujita, 1988; Shinoda et al., 1989), and that some of the olfactory receptor subclasses project to the specified glomeruli in topographically related regions, irrespective of their origins within the nasal epithelium (Fujita et al., 1985; Mori et al., 1985; Imamura et al., 1985; Schwob and Gottlieb, 1986; Mori, 1987; Shinoda et al., 1989).

These foregoing observations raise a question of how diverse olfactory axon subclasses are navigated toward their specified termination sites. This question, in particular, seems essential in the amphibian olfactory system, because all of the olfactory axons in amphibia are first united into a single compact fiber bundle, then project to different glomeruli. Thus, it will be of interest whether the amphibian olfactory receptors consist of different subclasses, how the olfactory pathways are organized, and moreover, what cellular cues are involved in the fasciculation and guidance of olfactory axon subclasses.

To answer the questions, we performed immunohistochemistry on the olfactory system of Xenopus tadpoles by using monoclonal antibodies A5 (MAbA5) and B2 (MAbB2) which recognize different cell surface proteins in Xenopus nervous tissues (Takagi et al., 1987), in combination with anatomical trac- 
ings of the olfactory pathways. As reported in a previous article (Takagi et al., 1987), MAbA5 binds to the superficial neuropils of the optic tectum where the optic nerve makes synaptic contacts with tectal neurons. Molecular cloning has indicated that the antigen recognized by MAbA5 is a unique type I membrane protein with motives homologous to the complement component and coagulation factor (Takagi et al., 1991). In the previous articles we conventionally referred to the antigen for MAbA5 as A5 (Takagi et al., 1987; Fujisawa et al., 1989, 1990; Takagi et al., 1991; Hirata et al., 1993). Hereafter, we will call the antigen neuropilin, a cell surface protein expressing in neuropils. The neuropilin is expressed on cell processes of particular types of neuron in developing Xenopus tadpoles (Takagi et al., 1987; 1991), and has been expected to be involved in neuronal recognition (Fujisawa et al., 1989) and in ncuritc outgrowth (Hirata et al., 1993). The antigen recognized by MAbB2 is expressed in the tectal neuropils (Takagi et al., 1987) and in the plexiform layers of the neural retina (Ohta et al., 1992). The serum antibodies generated against the antigen for MAbB2 impeded the formation of the retinal plexiform layers (Ohta et al., 1992). Our recent molecular cloning shows that the antigen for MAbB2 is a unique type I membrane protein with cell adhesion property (Ohta et al., unpublished observations). Thus, we will name the antigen for MAbB2 as plexin, a cell surface protein involved in the organization of plexiform layers.

In this article we report that the olfactory receptors and axons in Xenopus tadpoles are divided into several groups, defined on the basis of expression levels of the neuropilin and the plexin. The vomeronasal system consists of plexin-expressing axons, while axons in the principal olfactory system are divided into at least two subclasses which express both the neuropilin and the plexin to different degrees. Furthermore, we report that the principal olfactory axon subclasses are initially intermingled with each other within the olfactory nerve, but are gradually segregated, and eventually projected to specified glomeruli in topographically related regions within the main olfactory bulb. We also present anatomical data indicating the gradual segregation of the olfactory pathways. On the basis of these findings we discuss possible roles of these two cell surface proteins, the neuropilin and the plexin, in the organization of the olfactory pathways and connections.

\section{Materials and Methods}

Animals. Xenopus laevis tadpoles at stages 48 and 55 of development (Nieuwkoop and Farber, 1956) were purchased from Hamamatu Seibutsu Kyozai (Shizuoka, Japan).

Terminology. In the literatures receptors in the principal olfactory system are usually called olfactory receptors. Ilowever, in this article, we use "olfactory receptor" as a more general term indicating receptors in both the principal olfactory system and the vomeronasal system. Instead, we adopt a term "principal olfactory receptor" for receptors in the principal olfactory system.

Dil labeling. Anatomical mappings of the olfactory pathways and projections were done after labeling of olfactory axons with the lipophilic dye 1,1-dioctadecyl-3,3,3',3'-tetramethylindocarbocyanine perchlorate (Dil; Molecular Probes, Eugene, OR). The tadpoles at stage 55 were fixed with $4 \%$ paraformaldehyde in half-strength of $0.1 \mathrm{M}$ phosphatebuffered saline (PBS, $\mathrm{pH} \mathrm{7.4),} \mathrm{and} \mathrm{then} \mathrm{the} \mathrm{nose,} \mathrm{olfactory} \mathrm{and} \mathrm{vomero-}$ nasal nerves, and cerebrum were dissected free as a whole. To label olfactory axons anterogradely or retrogradely with the lipophilic dye Dil, small crystals of the dye were inserted into either nasal chamber or the rostral part of the cerebrum wherc olfactory axons terminated, respectively. To label whole length of olfactory axons with the dye, the specimens were kept in the fixative for $10 \mathrm{~d}$ at $37^{\circ} \mathrm{C}$, and then examined with an epifluorescence microscope (Olympus BHT-RFK) equipped with a rhodamine filter.

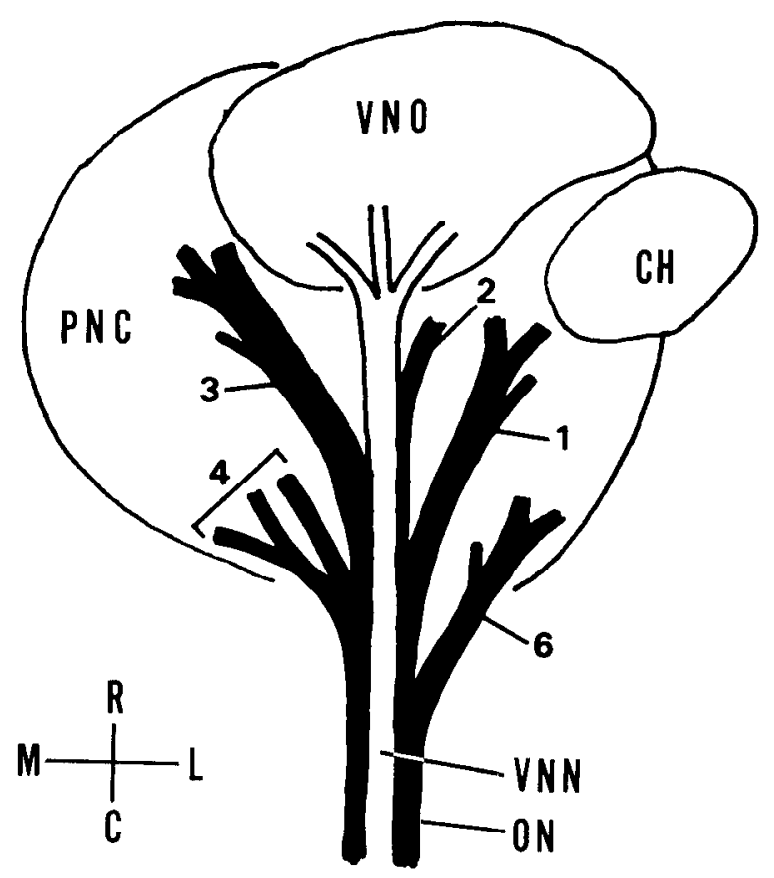

Figure 1. A schematic representation of the fasciculation patterns of olfactory axons in Xenopus tadpoles at stage 55 (a ventral view of the left nasal chamber). The principal olfactory axons derived from different parts within the principal nasal chamber $(P N C)$ are fasciculated into six major olfactory fiber bundles $(O F B ; 1-6)$ : The axons derived from the rostrolateral, rostrocentral, and rostromedial parts of the chamber form the OFB1, OFB2, and OFB3, respectively. The axons from the caudolateral, caudocentral, and caudomedial parts of the chamber are fasciculated into the OFB6, OFB5, and OFB4, respectively. The OFB5 is located dorsally to the other OFBs, and not visible by the ventral view. All OFBs are joined into the olfactory nerve $(O N)$. The axons form the vomeronasal organ $(V N O)$ are fasciculated into the vomeronasal nerve $(V N N)$ which runs along the ventral aspect of the olfactory nerve. $C H$, the choana; $R$, rostral; $C$, caudal; $M$, medial; $L$, lateral.

The topography in the olfactory projection was analyzed after preferential labeling of small regional groups of olfactory axons with the lipophilic dye Dil. In Xenopus tadpoles at stage 55 principal olfactory axons derived from different parts of the principal nasal epithelium are fasciculated into major six fiber bundles, at the ventral aspect of the nasal chamber. The fasciculation patterns are fairly stereotyped. Thus, we refer to these six fiber bundles as olfactory fiber bundles (OFBs), as schematically shown in Figure 1. To label a particular OFB with the lipophilic dye Dil, we cut off the remainders, and then put the dye on either the nasal chamber or the main olfactory bulb. As the OFB 2 and the vomeronasal nerve were not separable from each other, they were labeled as a whole.

Immunohistochemistry. Frozen sections of Xenopus tadpoles at stages 48 and 55 were prepared by a procedure reported elsewhere (Takagi et al., 1987). In brief, tadpoles were fixed with $4 \%$ paraformaldehyde in half-strength PBS for $2 \mathrm{hr}$ at $4^{\circ} \mathrm{C}$, immersed overnight in PBS containing $20 \%$ sucrose at $4^{\circ} \mathrm{C}$, and then embedded in OCT compound (Tissue Tek II, Miles). Serial coronal sections ( $20 \mu \mathrm{m}$ thick) were thaw-mounted on cover glasses coated with gelatin/chrome alum. Alternative sections were labeled with either monoclonal antibodies A5 (MAbA5) or B2 (MAbB2) (10 $\mu \mathrm{g}$ of affinity-purified IgGs dissolved into $1 \mathrm{ml}$ of PBS), and then with fluorescein-conjugated goat anti-mouse IgG (Cappel Labs: 70 times diluted with PBS).

Immunoblotting. The antigens recognized by either MAbA5 or MAbB2 were immunoprecipitated from the olfactory tissues including the vomeronasal organ, the principal nasal chamber, and the olfactory and vomcronasal nerves of 40 tadpoles at stage 55, following the procedurcs reported (Takagi et al., 1987; Ohta et al., 1992). Immunoblotting of the affinity purified antigens was performed as described by Towbin et al. (1979); the antigens were electrophoresed on $5 \%$ polyacrylamide gel according to Laemmli (1970), and then transferred to nitrocellulose 
filters. As neither MAbA5 nor MAbB2 was adequate for immunoblotling, a neuropilin-specific mouse monoclonal antibody 1 G7 (MAb1G7; $50 \mu \mathrm{g}$ of $\mathrm{IgG} / \mathrm{ml}$; Hirata et al., 1993) and a guinea pig anti-plexin antiserum (100 times in dilution; Ohta et al., 1992) were adopted.

\section{Results}

\section{Anatomical mapping of olfactory projections}

Several studies have indicated cytoarchitectures for the amphibian olfactory system (Scalia, 1976; Burton, 1990; Burton et al., 1990). However, little is known about the anatomical features for the olfactory projections. Thus, before describing ccll surface properties for olfactory axons, precise pathways, and projection patterns for both the vomeronasal and principal olfactory axons in Xenopus tadpoles at stage 55 are given.

Overall patterns of the olfactory projections were demonstrated after anterograde labeling of both the vomeronasal and principal olfactory axons with the lipophilic dye Dil, in wholemounted specimens (Fig. $2 A, B$ ). All of the vomeronasal and principal olfactory axons are joined into a single fiber bundle, and arrive at the main or accessory olfactory bulbs within the rostral end of the cerebral hemisphere. Insertion of small crystals of the lipophilic dye Dil into the vomeronasal organ resulted in a preferential labeling of the vomeronasal axons, and clarified their pathways (Fig. $2 C$ ): At the proximal position (the position close to the nose), the vomeronasal axons are joined into a single fiber bundle; the vomeronasal nerve. The vomeronasal nerve runs along the ventral aspect of the olfactory nerve, and then gradually shifts to the lateral. At the distal position (the position close to the cerebrum), the vomeronasal nerve leaves the olfactory nerve, and runs along the rostrolateral surface of the cerebrum to the accessory olfactory bulb. None of dye-positive vomeronasal axons arrive at the main olfactory bulb (Fig. 2C). However, when the olfactory nerve was preferentially labeled with the dye, all dye-positive axons arrive at the main olfactory bulb, but not at the accessory olfactory bulb (Fig. 2D).

In the main olfactory bulb the principal olfactory axons form spherical terminals so-called glomeruli (Burton et al., 1990). On the basis of the findings obtained by the dye-labeling of the principal olfactory axons (Fig. $2 A, B, D$ ) and by immunohistochemical analyses (described in the later part of this article), we conventionally divided the terminals of the principal olfactory axons into three regional groups; rostromedial (RM), intermediate (IM), and caudolateral (CL) groups of glomeruli, as schematically shown in Figure $2 E$. Each glomerular group is consisted of several smaller subgroups of glomeruli; some of them are located at the pial surface of the cerebrum (Fig. $2 A, B, D$ ), but others are in the deeper parts of the main olfactory bulb, and are not visible in the whole-mounted specimens (see Fig. 6).

To examine the topography in the projections of the principal olfactory axons, we separately labeled the olfactory fiber bundles (OFBs: see Fig. 1) with the lipophilic dye Dil. When a particular OFB was retrogradely labeled with the dye, a discrete part of the principal nasal epithelium becomes dye positive (Fig. 3A, $B$ ), indicating that the principal olfactory axons are selectively fasciculated into six OFBs depending on their positions within the principal nasal epithelium. The axons in the OFB1, OFB2, or OFB3 derive from the rostrolateral, rostrocentral, or rostromedial parts of the principal nasal epithelium, respectively. The axons in the OFB6, OFB5, or OFB4 come from the caudolateral, caudocentral, or caudomedial parts of the epithelium, respectively. On the contrary, the anterograde labeling of the OFBs with the dye shows that the axons in each OFB are widely distributed over the main olfactory bulb (Fig. $3 C-H$ ), even though the axons in the OFB2 tend to arrive at intermediate parts of the main olfactory bulb (Fig. $3 D$ ). These findings indicate that the projections of the principal olfactory axons do not show a clear spatial correspondence between the principal nasal epithelium and specific glomeruli within the main olfactory bulb, and suggest that the principal olfactory axons may change their topographic relationship during their courses from the nose to the terminal regions.

\section{Expression of a cell surface protein plexin in vomeronasal receptors and axons}

To examine cell surface properties of olfactory receptors and their axons, we performed immunohistochemistry on the olfactory system of Xenopus tadpoles at stage 55 by using monoclonal antibodies A5 (MAbA5) and B2 (MAbB2) which recognize different cell surface proteins, the neuropilin and the plexin, respectively.

Most cells in the vomeronasal epithelium and fine fascicules of the vomeronasal axons beneath the epithelium are intensely stained with MAbB2 (Fig. $4 A$ ) but not with MAbA5 (data not shown), indicating that the vomeronasal receptors and their axons express the plexin, but not the neuropilin. After leaving the vomeronasal organ the MAbB2-positive vomeronasal axons are further grouped into the larger fiber bundles which run caudally through the Bowman's glands (Fig. $4 B$ ), and eventually merge into a single fiber bundle, the vomeronasal nerve (Fig. $4 C, E)$. As the vomeronasal nerve is heavily stained with MAbB2 but not with MAbA5 (compare Fig. $4 C, E$ ), the pathways of the vomeronasal nerve are easily distinguished from the olfactory nerve. The MAbB2-positive and MAbA5-negative vomeronasal nerve runs along the ventral aspect of the olfactory nerve at its proximal parts (Fig. $5 A, B, E, F$ ), and lateral position at the distal parts (Fig. $5 C, D, G, H$ ), and then leaves the olfactory nerve for the accessory olfactory bulb (Fig. 6).

\section{Expression of cell surface proteins neuropilin and plexin in principal olfactory receptors and axons}

At stage 55 the length of the olfactory nerve (the distance between the center of the principal nasal chamber and the rostral tip of the main olfactory bulb) is about $2.8 \mathrm{~mm}$. The patterns of immunostaining for $\mathrm{M} \Lambda \mathrm{b} \Lambda 5$ and $\mathrm{MAbB} 2$ in the olfactory nerve are variant at different levels of the nerve.

The cells in the principal nasal epithelium are stained with MAbB2 (Fig. 4D), but not with MAbA5 (data not shown). However, fine bundles of principal olfactory axons around the nasal chamber are stained by both antibodies (Fig. $4 C, E$ ). The intensity of the immunostainings for each antibody is different among the axon bundles: some bundles are strongly stained with MAbA5 but weakly with MAbB2; vice versa, the others are strongly stained with MAbB2 but weakly with MAbA5. A group of axon bundles are moderately stained with both antibodies. These observations suggest that the principal olfactory receptors express not only the plexin but also the neuropilin, even though the principal olfactory epithelium is not stained with MAbA5. The negative immunostaining in the principal olfactory epithelium with MAbA5 seems reasonable, because the antigen for MAbA5 is expressed on the surfaces of axons but not of cell somata in tadpole brains (Takagi et al., 1987).

After leaving the nasal chamber the fine bundles of the principal olfactory axons become grouped into six larger bundles, 

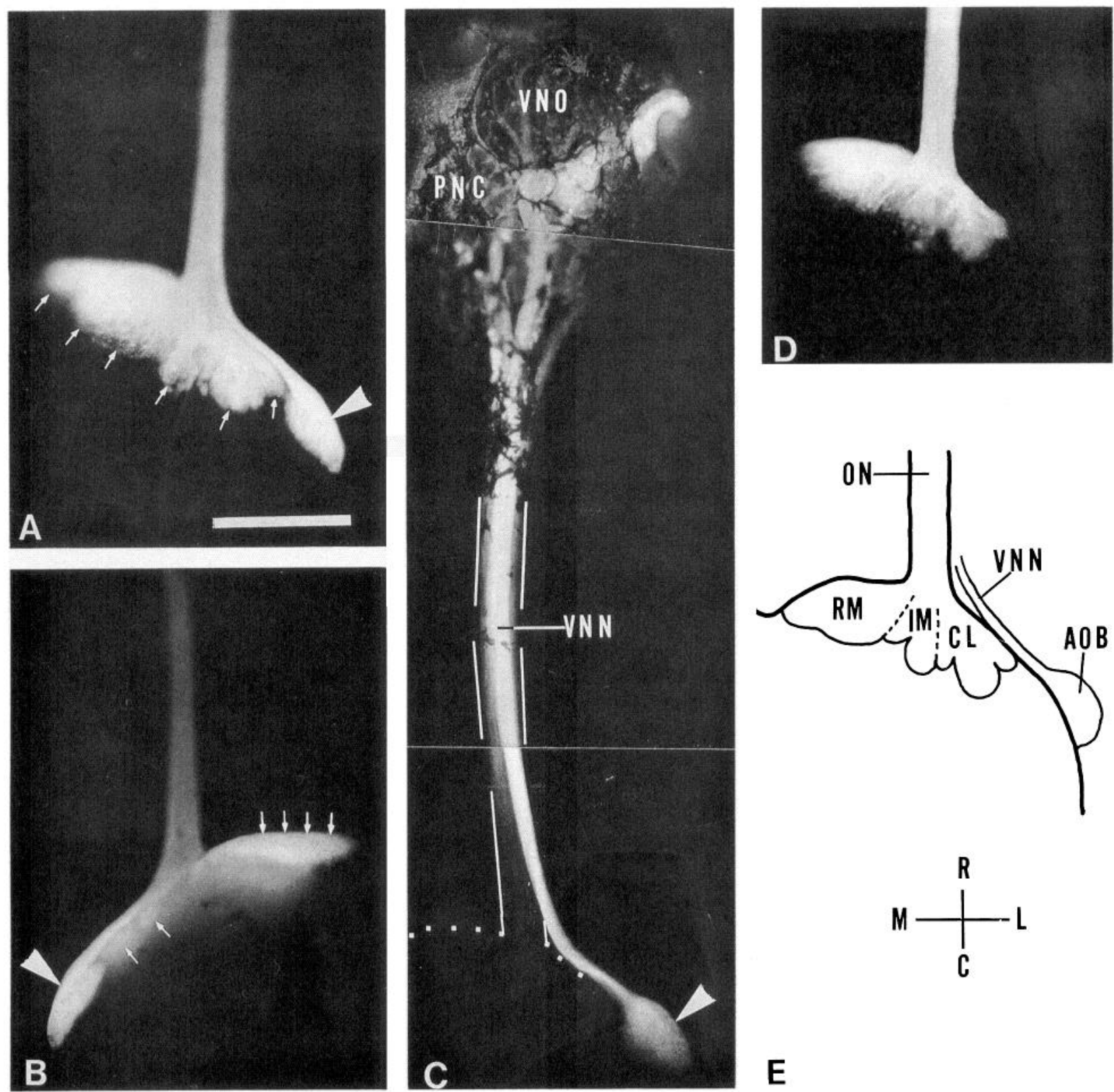

Figure 2. Pathways and projection patterns of olfactory axons in Xenopus tadpoles at stage 55 detected by anterograde labeling of olfactory axons with the lipophilic dye Dil. $A$ and $B$ Ventral $(A)$ and dorsal $(B)$ views of the left cerebrum of a tadpole in which both the olfactory nerve and the vomeronasal nerve were labeled with the dye. The dye-positive olfactory axons arrive at the main olfactory bulb (arrows) and the accessory olfactory bulb (arrowheads). C, A ventral view of the left olfactory projection of a tadpole in which the vomeronasal nerve was preferentially labeled with the dye. The vomeronasal nerve $(V N N)$ runs along the ventral aspect of the olfactory nerve (outlined by parallel lines), then leaves the olfactory nerve for the accessory olfactory bulb (an arrowhead). A dotted line indicates the rostral margin of the left cerebrum. PNC, the principal nasal chamber; $V N O$, the vomeronasal organ. $D$, A ventral view of the left olfactory projection of a tadpole in which the vomeronasal organ had been abrated, then the principal olfactory axons were labeled with the dye. All dye-positive axons terminate within the main olfactory bulb, but not in the accessory olfactory bulb. E. A schematic representation of the patterns of the olfactory projection in Xenopus tadpoles at stage 55. The terminals of olfactory nerve $(O N)$ within the main olfactory bulb are divided into three regional groups of glomeruli; the rostromedial $(R M)$, intermediate $(I M)$, and caudolateral $(C L)$ groups of glomeruli. $V N N$, the vomeronasal nerve; $A O B$, the accessory olfactory bulb. The axes in each figure except $B$ is as shown in $E$. $R$, rostral; $C$, caudal; $M$, medial; $L$, lateral. In $B$ the left and right sides of the figure are the lateral and the medial, respectively. Scale bar (in $A$ ), $500 \mu \mathrm{m}$ for $A-E$.

the OFBs (Fig. $5 A, E$; and see Fig. 1), then are merged into a single fiber bundle, the olfactory nerve at about one-third distal level of the olfactory pathway (at $2 \mathrm{~mm}$ before the main olfactory bulb; Fig. $5 B, F$ ). The bindings of MAbA5 are slightly prominent in the medial OFBs (Fig. $5 A$ ) and in the medial part of the olfactory nerve (Fig. $5 B$ ), and the bindings of MAbB2 are slightly prominent in the lateral OFBs (Fig. $5 E$ ) and the lateral part of the nerve (Fig. $5 F$ ). Also, at these proximal levels of the olfactory pathway, segregation of the immunostainings for both antibodies partly occurs; for example, the immunostainings for MAbB2 in both the OFB3 and OFB4 become heterogeneous when they merge with each other, and the bindings of the MAbB2 in the OFB5 also become heterogeneous (compare Fig. $5 E, F$ ).

As the olfactory nerve gets close to the cerebrum, the segre- 

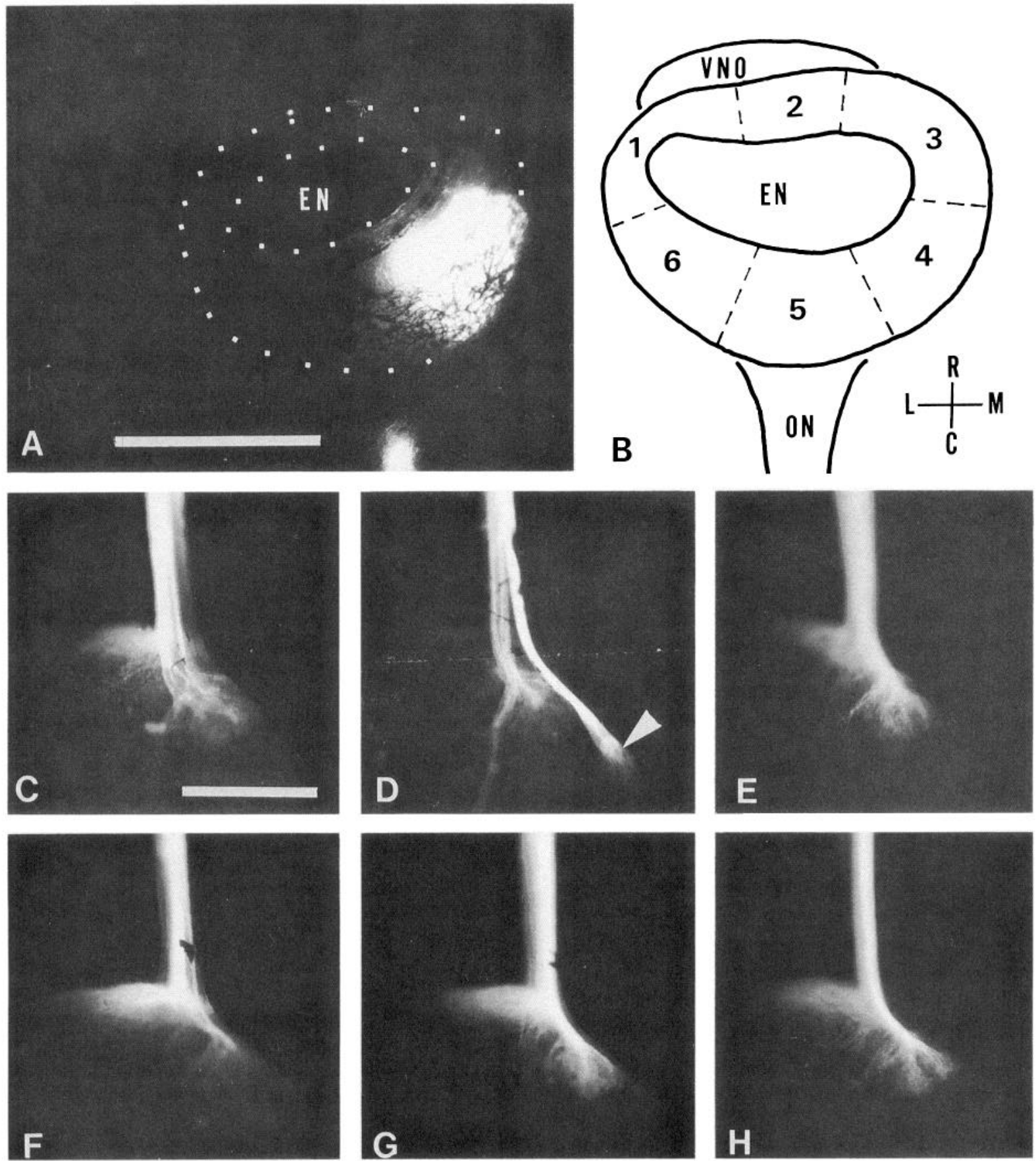

Figure 3. Topographies of the olfactory projection in Xenopus tadpoles at stage 55 detected by selective labeling of the OFBs (see Fig. 1) with the lipophilic dye Dil. A, A dorsocaudal view of the left nasal chamber (outlined by dotted lines) after the retrograde labeling of the OFB4 with the dye. A caudomedial part of the principal nasal chamber becomes dye positive, indicating the origin for the OFB4 within the principal nasal epithelium. $E N$, the external naris. $B$, A schematic representation of the origins for each OFB within the principal nasal epithelium detected by the retrograde labeling of the OFBs with the dye (a dorsal view of the left nasal chamber). The numbers $1-6$ indicate the dye-positive areas after labeling the OFBs 1 to 6 , respectively. $V N O$, the vomeronasal organ; $E N$, the external naris; $O N$, the olfactory nerve. $R$, rostral; $C$, caudal; $M$, medial; $L$, lateral. The axes in $B$ also apply to $A$. $C-H$, Projections of the OFB $1(C)$, OFB2 $(D)$, OFB3 $(E)$, OFB6 $(F)$, OFB5 $(G)$, and OFB4 $(H)$ within the main olfactory bulb (ventral views of the left cerebrums). When the OFB2 was labeled with the dye, the vomeronasal nerve projected to the accessory olfactory bulb (an arrowhead) becomes dye positive $(D)$. The top and the bottom of each figure are the rostral and the caudal, respectively. The left and right sides of each figure are the medial and the lateral, respectively. Scale bars: $A, 500 \mu \mathrm{m} ; C, 500 \mu \mathrm{m}$ for $C-H$.

gation of the immunostainings for MAbA5 and MAbB2 proceeds. At about two-third distal level of the olfactory nerve (at $1.1 \mathrm{~mm}$ before the main olfactory bulb), the section of the nerve is roughly divided into two areas by virtue of the intensity of the immunostainings for each antibody; the dorsomedial half of the olfactory nerve is strongly stained with MAbA5 but weakly with MAbB2; vice versa, the ventrolateral half of the nerve is strongly stained with MAbB2 but weakly with MAbA5 (compare Fig. $5 C, G$ ). The boundaries for both the MAbA5-prominent and MAbB2-prominent areas are mostly sharp. Further- 

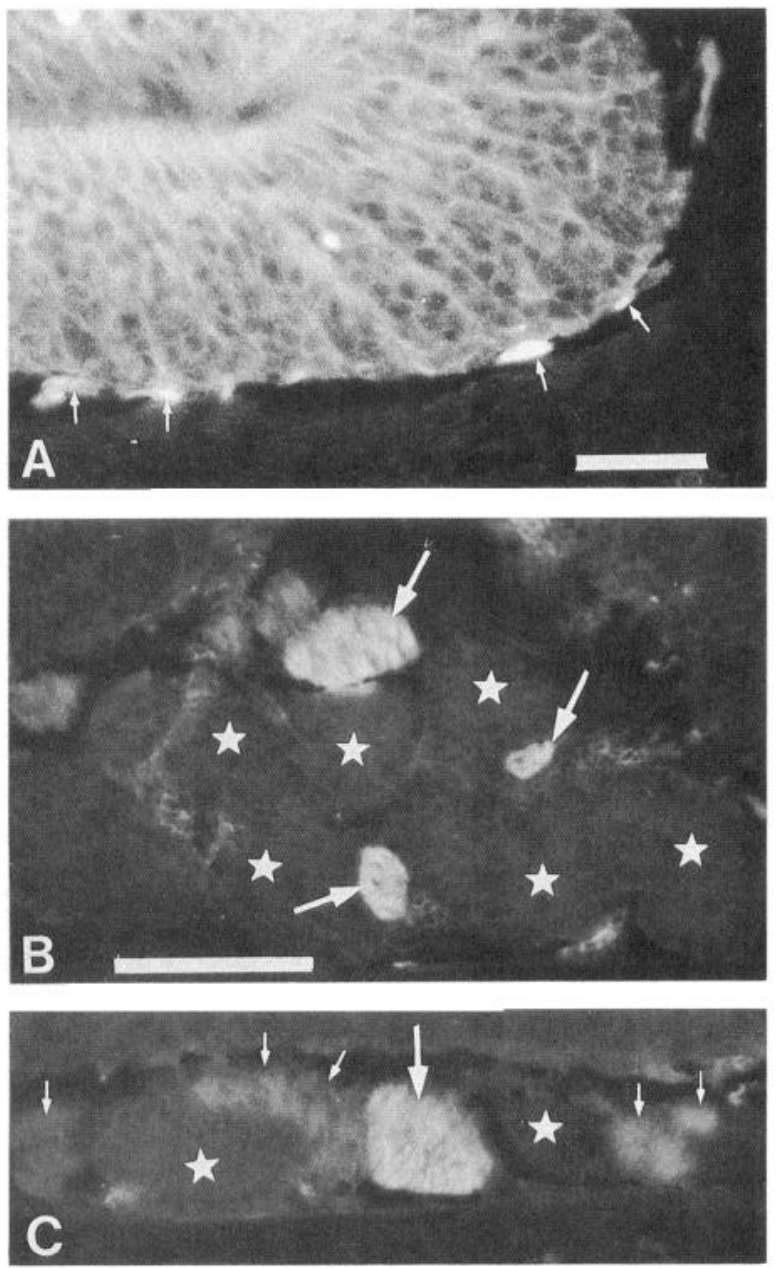
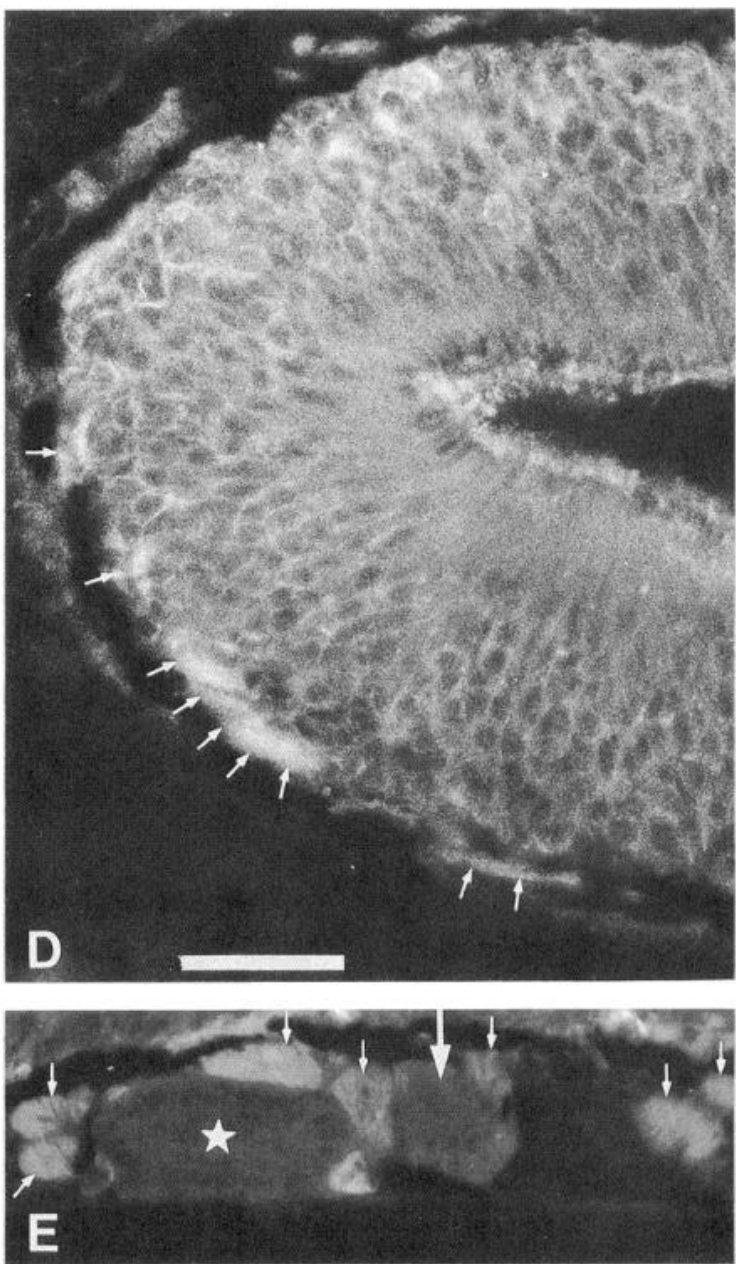

Figure 4. Immunofluorescent staining of the olfactory receptors and axons in a Xenopus tadpole at stage 55 with MAbB2 (A-D) and MAbA5 (E). $A$, Almost all cells in the vomeronasal epithelium and fine fascicles of vomeronasal axons (small arrows) beneath the epithelium are positively stained with MAbB2. B, Bundles of the vomeronasal axons (large arrows) among the Bowman's glands (asterisks) are positively stained with MAbB2. $C$, The vomeronasal nerve (a large arrow) is stained with MAbB2. Bundles of the principal olfactory axons (small arrows) are also stained by MAbB2 in different degrees. Asterisks, the Bowman's glands. D, Most cells in the principal olfactory epithelium and fine fascicles of principal olfactory axons (small arrows) beneath the epithelium are stained with MAbB2. $E$, An adjacent section to the one in $C$ was stained with MAbA5. The vomeronasal nerve (a large arrow) is negative for MAbA5-immunostaining. Bundles of the principal olfactory axons (small arrows) are stained with MAbA5 in different degrees. Asterisk, the Bowman's gland. Scale bars: $A$ and $D, 50 \mu \mathrm{m} ; B, 200 \mu \mathrm{m}$ for $B, C$, and $E$.

more, the MAbA5- or MAbB2-prominent areas in one section are nearly corresponded to the areas with less immunostaining for MAbB2 or MAbA5 in the adjacent section, respectively. At the distal end of the olfactory nerve the MAbA5-prominent and the MAbB2-prominent areas are completely segregated each other: the dorsomedial half of the nerve is strongly and almost homogeneously stained with MAbA5 but weakly with MAbB2, while the ventrolateral half of the nerve is strongly and homogeneously stained with MAbB2 but weakly with MAbA5 (compare Fig. 5D,H).

The antigens for both MAbA5 and MAbB2 are expressed in neurons but not in glial cells (Takagi et al., 1991; Ohta et al., 1992). Thus, the regionally different immunostainings for MAbA5 and MAbB2 within the olfactory nerve suggest that the olfactory nerve consists of at least two subclasses of the principal olfactory axons: the axons with high levels of the neuropilin (the antigen for MAbA5) and low levels of the plexin (the antigen for MAbB2), and the axons with high levels of the plexin and low levels of the neuropilin. In this article, we refer to the former as neuropilin-predominant principal olfactory axons, and the latter as plexin-predominant principal olfactory axons. The finding that the segregation of the immunostainings for MAbA5 and $\mathrm{MAbB} 2$ is clear at the distal parts of the olfactory nerve but not so clear at the proximal parts indicates that the neuropilinpredominant and plexin-predominant principal olfactory axons are initially mixed with each other, and then sorted out (see the Discussion).

\section{Projection patterns of principal olfactory axon subclasses}

Immunohistochemistry of serial coronal sections of the cerebrum reveals that the main olfactory bulb is stained with both MAbA5 and MAbB2 in different degrees (Fig. 6). The glomeruli located at the rostromedial part of the main olfactory bulb (the RM group of glomeruli) are heavily stained with MAbA5, and weakly with MAbB2. While, the caudolateral group of glomeruli (the CL group) is heavily stained with MAbB2, and weakly with MAbA5. The IM glomerular group are strongly stained with both antibodies. MAbA5 does not bind to the accessory olfactory bulb, whereas MAbB2 strongly binds to it (compare Fig. $6 B, D)$. 

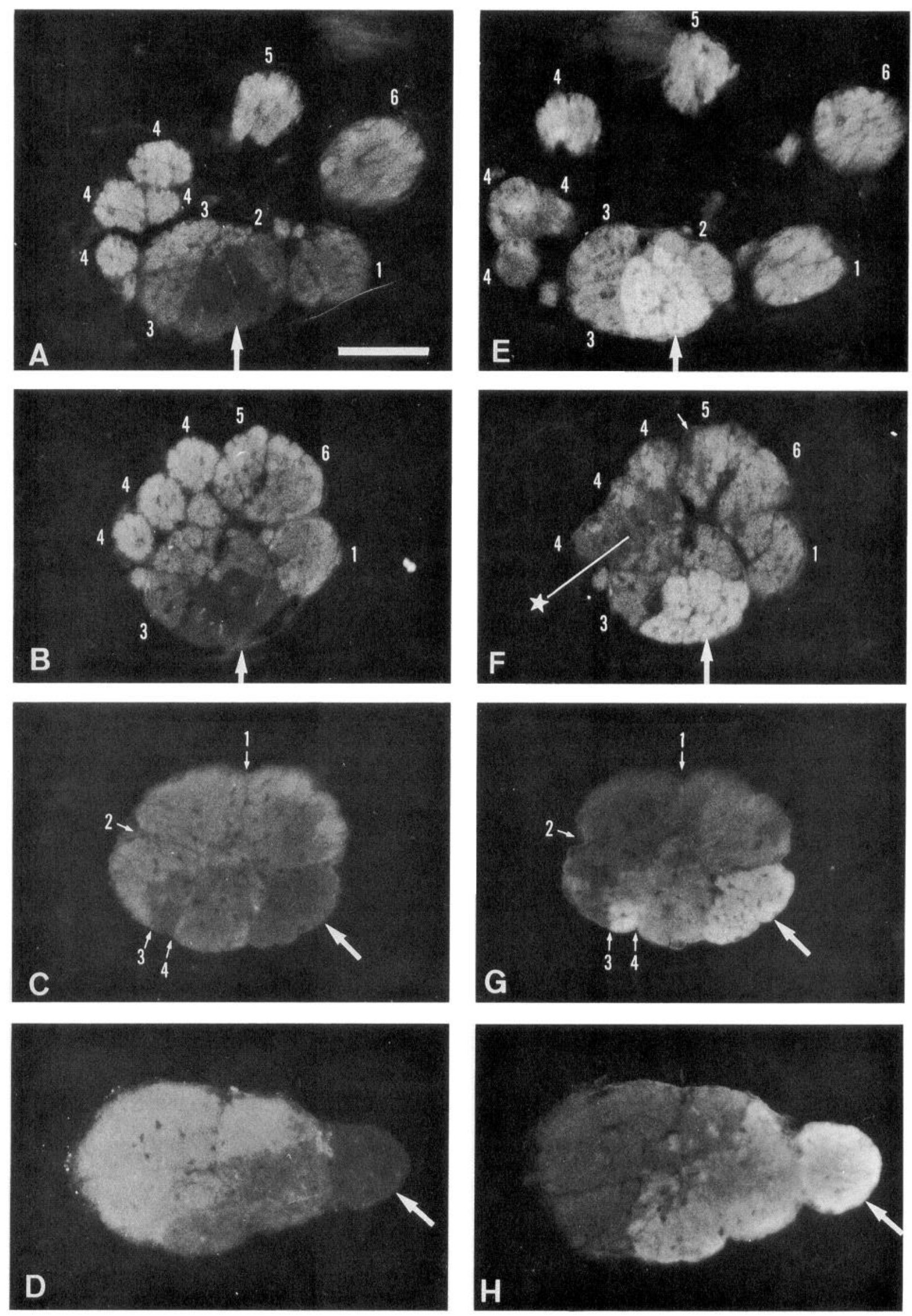
These findings indicate that the terminals of the principal olfactory axon are segregated according to their cell surface labels: the neuropilin-predominant axons preferentially terminate at the RM gromerular group, and the plexin-predominant axons at the CL glomerular group. It is not clear whether the IM glomerular group is innervated by the neuropilin-predominant and plexin-predominant axon subclasses or by a third principal olfactory axon subclass in which both the neuropilin and plexin are strongly expressed (see the Discussion).

\section{Expression patterns of neuropilin and plexin in the olfactory system of young tadpoles}

The binding patterns for both MAbA5 and MAbB2 in the olfactory system of Xenopus tadpoles at stage 48 are fundamentally the same as that in the tadpoles at stage 55 . The vomeronasal nerve is stained with MAbB2, but not with MAbA5 (Fig. 7). The MAbB2-positive and MAbA5-ncgative vomcronasal nerve runs along the ventral aspect of the olfactory nerve at the proximal levels (Fig. $7 A, B, E, F$ ), and then shifts to the lateral (Fig. $7 C, G$ ), while the olfactory nerve is stained with both MAbA5 and MAbB2. The length of the olfactory nerve is about $650 \mu \mathrm{m}$, at this stage. At the one-third distal position of the olfactory nerve (at $420 \mu \mathrm{m}$ before the main olfactory bulb), the immunostainings for each antibody are almost homogeneous (Fig. $7 A, E$ ) except the dorsolateral part of the nerve where the binding of MAbA5 is slightly weak (Fig. $7 A$ ). At the two-thirds distal position of the olfactory nerve (at $220 \mu \mathrm{m}$ before the main olfactory bulb), immunostainings for MAbA5 are prominent in the medial part but weak in the lateral part of the nerve (Fig. $7 B$ ). There is no clear regional difference in the immunostainings for MAbB2 (Fig. $7 F$ ). At the distal end of the olfactory nerve (Fig. $7 C, G$ ) and in the main olfactory bulb (Fig. 7D, $H$ ), MAbA5 predominantly binds to the medial parts, and MAbB2 to the lateral parts. These findings suggest that, at stage 48 , the olfactory nerve is consisted of axon subclasses which are differentially labeled with the neuropilin and the plexin, and further that the pathways for these axon subclasses are segregated according to their cell surface labels, even though the segregation of the pathways is not so clear as in the tadpoles at stage 55 .

\section{Characterization of antigens for $M A b A 5$ and $M A b B 2$}

To confirm that the target molecules for MAbA5 and MAbB2 in the olfactory system are the same as the ones in the brain, the antigens for MAbA5 and MAbB2 were affinity purified from the olfactory tissues (including the vomeronasal organ, the principal nasal chamber, and the olfactory and vomeronasal nerves) of tadpoles at stage 55, and then were prepared for immunoblot analyses. In the immunoprecipitates by MAbA5 a peptide comigrating at a $140 \mathrm{kDa}$ position in SDS-PAGE is positively stained with a neuropilin-specific antibody 1G7 (Fig. 8, lane 2). Furthermore, in the immunoprecipitates by MAbB2 a peptide at $220 \mathrm{kDa}$ position is immunoreactive for an anti-plexin anti- serum (Fig. 8, lane 3). The sizes of these two peptides are same to the ones of the antigens for MAbA5 and MAbB2 in tadpole brains (Takagi et al., 1987, 1991; Ohta et al., 1992), indicating that the target molecules for MAbA5 and MAbB2 in the olfactory system are the neuropilin and the plexin, respectively.

\section{Discussion}

In this article we have shown that the olfactory system in Xenopus tadpoles consists of several types of olfactory axons which are differentially labeled with two cell surface molecules, the neuropilin and the plexin, and further that the pathways for these axons are organized according to their cell surface labels.

\section{Differential labels of olfactory axons by neuropilin and plexin}

In mammalian olfactory systems several olfactory receptor subclasses have been identified by hybridoma techniques (Allen and Akeson, 1985a,b; Fujita et al., 1985; Imamura et al., 1985; Mori et al., 1985; Schwob and Gottlieb, 1986; Mori, 1987; Mori et al., 1987; Onoda and Fujita, 1988). The present immunohistochemistry with MAbA5 and MAbB2 distinguished vomeronasal receptors and at least two classes of principal olfactory receptors in Xenopus tadpoles.

The vomeronasal receptors and their axons are stained with MAbB2, but not with MAbA5. The immunoblot analysis shows that the target molecules for MAbA5 and MAbB2 in the olfactory system are the neuropilin and the plexin, respectively (see Fig. 8). Thus, we conclude that the vomeronasal receptors and axons are labeled with the cell surface molecule plexin, but not with the neuropilin. As the immunostaining for MAbB2 is homogeneous in the vomeronasal epithelium, the vomeronasal nerve and the accessory olfactory bulb, all of the vomeronasal axons seem to express the plexin. Though several axon subclasses have been identified in the rabbit vomeronasal system (Imamura et al., 1985; Mori, 1987; Mori et al., 1987), the present immunohistochemistry did not distinguish axon subclasses in the Xenopus vomeronasal system.

While the olfactory nerve was stained with both MAbA5 and $\mathrm{MAbB} 2$, the finding that the distal end of the olfactory nerve is distinctly divided into two areas with different immunostainings for both MAbA5 and MAbB2 (see Fig. $5 D, H$ ) enables us to predict that the olfactory nerve consists of at least two subclasses of principal olfactory axons: the neuropilin-predominant and the plexin-predominant axons. However, the observation that the terminals of the principal olfactory axon are divided into three regional groups with different immunostainings for MAbA5 and MAbB2 (see Fig. 6) may imply another principal olfactory axon subclass in which both the neuropilin and the plexin are strongly expressed. To test the possibility, we performed double-label immunohistochemistry on the same sections of the olfactory nerve by using neuropilin-specific and plexin-specific antibodies generated in different animal species; the mouse monoclonal antibody A5 (MAbA5) and the guinea

\footnotetext{
Figure 5. Immunofluorescent staining of serial sections of the olfactory and vomeronasal nerves in a Xenopus tadpole at stage 55 with MAbA5 and MAbB2. Adjacent two sections made at the OFB level (see Fig. 1) $(A, E)$, at about one-third distal level $(B, F)$, two-thirds distal level $(C, G)$, and distal end $(D, H)$ of the olfactory nerve were stained with MAbA5 $(A-D)$ and MAbB2 $(E-H)$. The numbers $1-6$ in $A, B, E$, and $F$ indicate the OFB1 to OFB6, respectively. Large arrows in each figure indicate the vomeronasal nerve. An asterisk in $F$ indicates a region with less-prominent immunostainings for MAbB2 appeared at the confluence of the OFB3 and OFB4. A small arrow in $F$ indicates a MAbB2-less prominent area appeared in the OFB5. Small arrows $1-4$ in $C$ and $F$ indicate positions corresponding between the two adjacent sections. The top and the bottom of each figure are the dorsal and the ventral, respectively. The left and right sides of each figure are the medial and the lateral, respectively. Scale bar (in $A$ ), $100 \mu \mathrm{m}$ for $A-H$.
} 

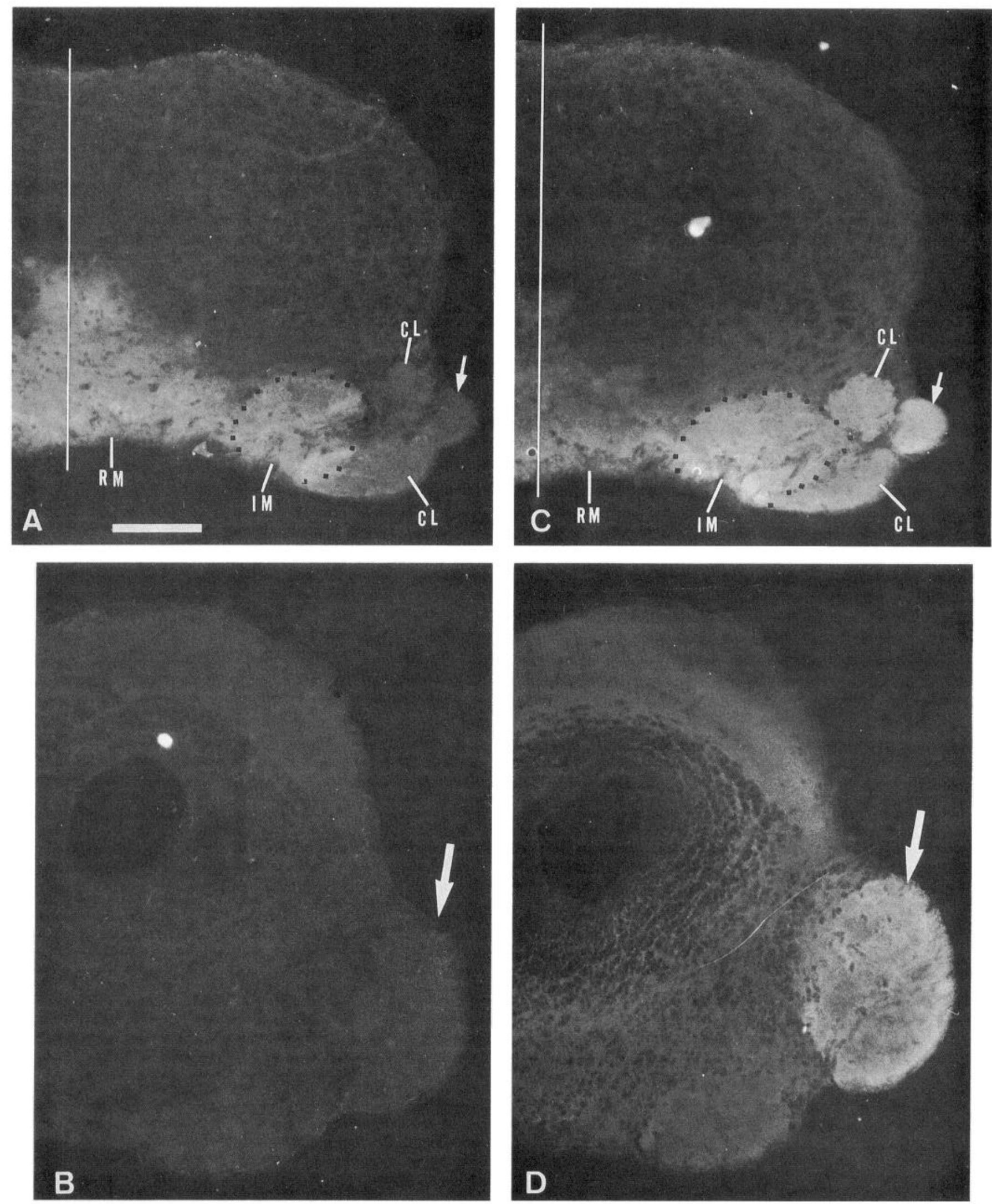

Figure 6. Immunofluorescent staining of the main olfactory bulb and the accessory olfactory bulb with MAbA5 in a Xenopus tadpole at stage 55 . Adjacent two sections made at the levels of the main olfactory bulb $(A, C)$ and the accessory olfactory bulb $(B, D)$ were stained with MAbA5 $(A, B)$ and MAbB2 $(C, D) . R M, I M$, and $C L$ indicate the rostromedial, intermediate, and caudolateral glomerular groups, respectively (see Fig. 2 and the text). Dotted lines in $A$ and $C$ outline the IM glomerular groups. The IM glomerular group is strongly stained with both MAbA5 and MAbB2 ( $A, C$ ). Arrows in $A$ and $C$ indicate the vomeronasal nerve. Arrows in $B$ and $D$ indicate the accessory olfactory bulb. The top and the bottom of each figure are the dorsal and the ventral, respectively. The left and right sides of each figure are the medial and the lateral, respectively. Vertical lines in $A$ and $C$ indicate the middle of the cerebrum. Scale bar (in $A$ ), $50 \mu \mathrm{m}$ for $A-D$. 

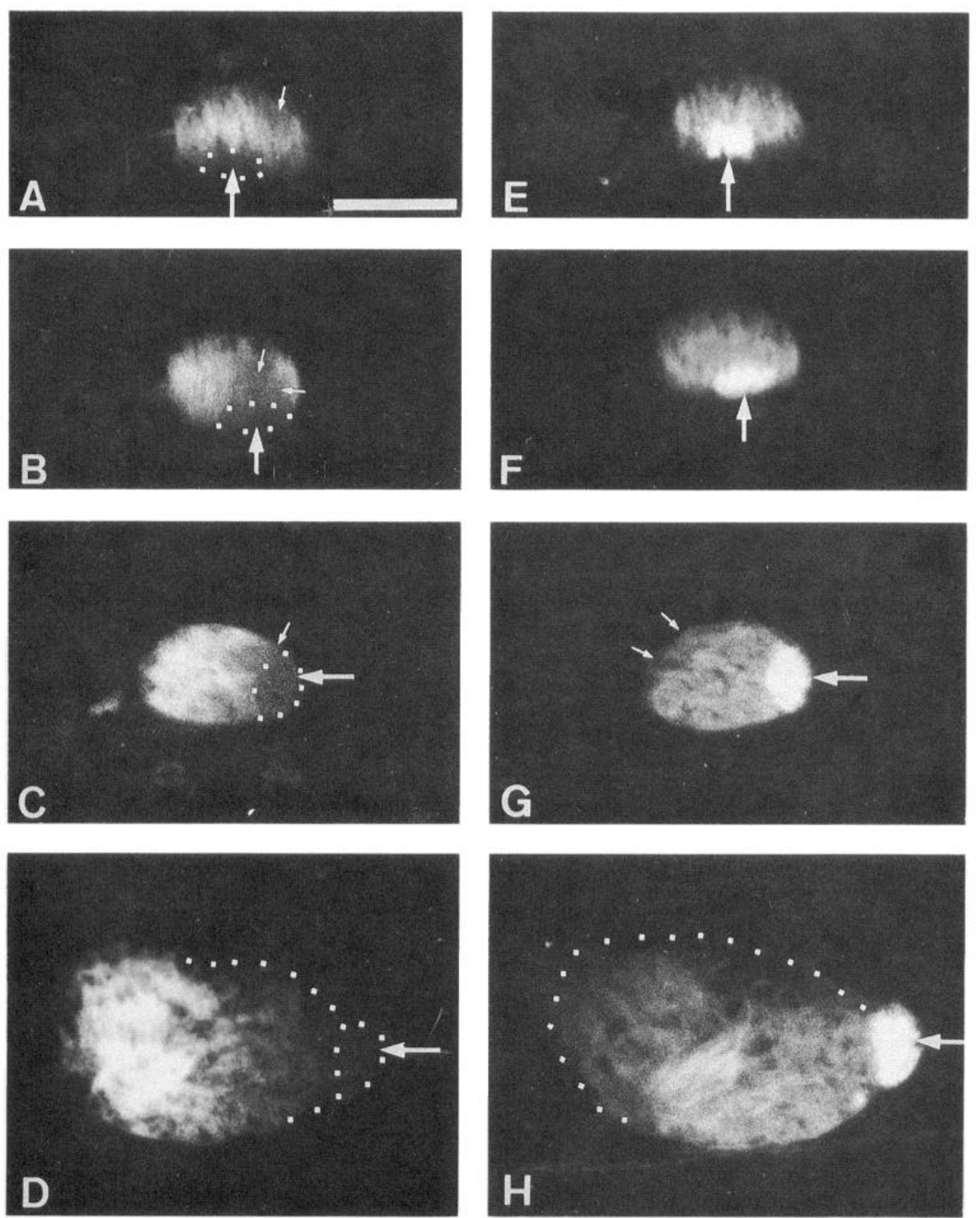

Figure 7. Immunofluorescent staining of the olfactory system in a Xenopus tadpole at stage 48 with MAbA5 and MAbB2. Adjacent two sections made at the one-third distal level $(A, E)$, twothirds distal level $(B, F)$, and distal end $(C, G)$ of the olfactory nerve, and at the level of the main olfactory bulb $(D, H)$ were stained with MAbA5 $(A-D)$ and MAbB2 $(E-H)$. Large arrows in each figure indicate the vomeronasal nerve. In $A-D$ the vomeronasal nerve is also outlined by dotted line. Dotted lines in $D$ and $H$ outline the margins of sections. Small arrows in $A-C$ and $G$ indicate MAbA5-less prominent and MAbB2-less prominent areas within the principal olfactory nerve, respectively. The top and the bottom of each figure are the dorsal and the ventral, respectively. The left and the right sides of each figure are the medial and the lateral. Scale bar (in $A$ ), $200 \mu \mathrm{m}$ for $A-H$. pig anti-plexin antiserum. However, we have not obtained evidence indicating that the olfactory nerve consists of an axon subclass that is strongly stained with both antibodies (unpublished observations). Thus, we can speculate that the olfactory nerve consists of both the neuropilin-predominant and the plexin-predominant axon subclasses, and further that the IM gromerular group may be dually innervated by these two axon subclasses.

In mammals some principal olfactory receptor subclasses are distributed in particular spatial patterns within the nasal epithelium (Pedersen et al., 1986; Schwob and Gottlieb, 1986; Shinoda et al., 1989). While the neuropilin-predominant and the plexin-predominant receptor subclasses found in Xenopus tadpole olfactory system seem to be widely distributed over the olfactory epithelium, because all of the OFBs derived from different parts of the nasal epithelium are stained with both MAbA5 and MAbB2. The findings that the immunostaining for MAbA5 is slightly intense in the medial OFBs than in the lateral OFBs, and that the immunostaining for MAbB2 is slightly stronger in the lateral OFBs than in the medial OFBs (see Fig. 5) indicate that the more neuropilin-predominant receptors are in the medial parts of the principal nasal epithelium, and the more plexinpredominant receptors in the lateral parts.

\section{Sorting of olfactory axon pathways according to their cell surface labels}

The present immunohistochemistry and neuroanatomical tracings offered two results implying how the pathways of the olfactory axons are organized in Xenopus tadpoles.

The first result is that the plexin-positive and neuropilinnegative vomeronasal axons form a discrete fiber bundle, even after they joined with the principal olfactory axons (see Figs. 5 and 7). The discrimination of the vomeronasal axons from the principal olfactory axons was also confirmed by the neuroanatomical tracings (see Fig. 2), indicating that the vomeronasal system and the principal olfactory system are completely sep- 


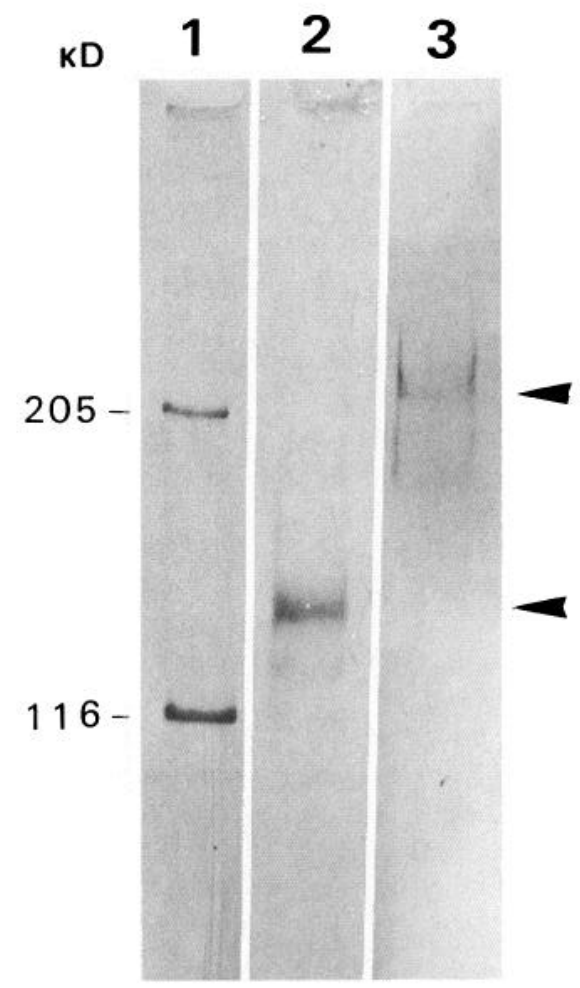

Figure 8. Identification of antigens for MAbA5 and MAbB2 in the olfactory system of Xenopus tadpoles at stage 55 by immunoblot. The antigens for MAbA5 and MAbB2 were affinity purified from the olfactory tissues, separated by SDS-PAGE ( $5 \%$ acrylamide gel), then transferred to nitrocellulose filters. The antigen for MAbA5 was detected by using a monoclonal antibody 1G7 which is specific for the neuropilin (lane 2). The antigen for MAbB2 was detected by using a guinea pig anti-plexin antiserum (lane 3). Upper and lower arrows indicate the positions for the plexin and the neuropilin, respectively. Lane 1, molecular weight markers at $205 \mathrm{kDa}$ and $116 \mathrm{kDa}$.

arated from each other in Xenopus tadpoles, even though the axons of both systems form a single fiber bundle. The pathway for the vomeronasal nerve observed in Xenopus tadpoles coincides well with that in other amphibian species (Scalia, 1976; Burton et al., 1990).

The second and most important result is that the immunostainings for both MAbA5 and MAbB2 within the olfactory nerve are gradually segregated throughout the course from the nose to the main olfactory bulb. The gradual segregation of the immunostainings is clearly shown in the olfactory nerve of tadpoles at stage 55: in the proximal parts of the olfactory nerve the immunostainings for both MAbA5 and MAbB2 are partially segregated, while the distal parts of the nerve are completely divided into the MAbA5-prominent and MAbB2-prominent areas (see Fig. 5). These findings indicate that the neuropilinpredominant and plexin-predominant principal olfactory axons are gradually segregated from each other to form larger and larger fiber bundles within the olfactory nerve, and eventually, completely sorted out. The pathway sorting of the principal olfactory axons inevitably comes to a conclusion that the axons rearrange their topographic relationships within the olfactory nerve. The rearrangement of the pathways of the principal olfactory axons is also deduced from the results obtained by the neuroanatomical mappings of the olfactory projection: the principal olfactory axons derived from particular parts of the prin- cipal olfactory epithelium diverged within the main olfactory bulb (see Fig. 3).

The rearrangement of the pathways of principal olfactory axons indicates that the principal olfactory projection in Xenopus tadpoles does not show strict spatial correspondence between the nasal epithelium and the olfactory bulb. The nontopographic olfactory projection observed in Xenopus tadpoles has also been reported in the trout (Riddle and Oakley, 1991, 1992; Riddle et al., 1993), and is contrasted to the projection patterns in mammalian olfactory systems where there are some degree of topographic organization between the nasal epithelium and the olfactory bulb (Land et al., 1970; Land, 1973; Land and Shepherd, 1974; Constanzo and O'Connell, 1978; Astic and Saucier, 1986; Saucier and Astic, 1986; Astic et al., 1987).

\section{Possible involvement of cell surface molecules neuropilin and plexin in the organization of the pathways and connections for the principal olfactory axons}

The present study shows that the pathways of the principal olfactory axon subclasses are spatially reorganized. There are two possible mechanisms to explain the spatial reorganization of the pathways.

The first, the neuropilin and the plexin which are differentially expressed on the principal olfactory axon subclasses act as cellular cues for selective axon fasciculation. In the Xenopus tadpoles at stage 55 , the segregation of the immunostainings occurs even at the proximal parts of the olfactory nerve. Also, the segregation of the MAbA5-prominent and MAbB2-prominent areas have almost been completed before the nerve arrives at the main olfactory bulb (at $1.1 \mathrm{~mm}$ before the main olfactory bulb) (see Fig. 5). These findings suggest that the mechanism of selective fasciculation is functional in the pathway sorting, at least in the tadpoles at stage 55 .

Our previous studies have shown that embryonic retinal axons express the antigen for MAbA5 (the neuropilin) (Fujisawa et al., 1990), and preferentially grow into the neuropilin-positive brain regions (Fujisawa et al., 1989). More recent analyses in vitro indicate that the neuropilin promotes neurite outgrowth via a homophilic mechanism (Hirata et al., 1993), while the antigen for MAbB2 (the plexin) is expressed in particular plexiform layers in the Xenopus tadpole brain and neural retina (Takagi et al., 1987; Ohta et al., 1992). The anti-plexin antibodies perturbed the formation of the retinal plexiform layers (Ohta et al., 1992). Furthermore, cloning and transfection analyses have clarified that the plexin is a novel homophilic cell adhesion molecule (Ohta et al., unpublished observations). These several lines of evidence have suggested that both the neuropilin and the plexin play roles in neuronal cell interactions, and enable us to predict the involvement of these two cell surface molecules in the interactions of the olfactory axons. Though the present immunohistochemical study does not directly prove the roles of the neuropilin and the plexin, the finding that the pathway segregation for the principal olfactory axons occurs according to their cell surface labels with these two molecules may indicate the involvement of the neuropilin and the plexin in the organization of the principal olfactory pathways. Both the neuropilin and the plexin may play a role in selective fasciculation for the neuropilin- and plexin-expressing principal olfactory axon subclasses to form the larger and larger fiber bundles.

As the pathways of the vomeronasal axons are completely separated from the ones of the principal olfactory axons throughout their courses, it is open to question whether the pathway 
sorting between the vomeronasal and principal olfactory axons also occurs according to their differential cell surface labels with the neuropilin and the plexin.

The finding that the pathways of the principal olfactory axons are sorted out depending on the expression levels of both the neuropilin and the plexin may raise some issues for the roles of these two cell surface molecules in neuronal cell interactions. The first is that the neuropilin and the plexin might act in a dose-dependent manner, as suggested for the neuronal cell adhesion molecule NCAM (Doherty et al., 1990a,b). The second is that the combination of these two cell surface molecules might regulate neuronal cell interactions. A number of studies have shown the cooperation of several cell surface molecules in axon fasciculation or neurite outgrowth (Bixby et al., 1987, 1988; Neugebauer et al., 1988; Furlcy ct al., 1990; Cervello et al., 1991; Lemmon et al., 1992; Sonderegger and Rathjen, 1992). It will he of interest to test whether the neuropilin and the plexin interact with each other, and also whether intracellular signaling pathways for these two cell surface molecules are linked, as suggested for NCAM and N-cadherin (Doherty et al., 1991).

The above selective fasciculation mechanism, however, seems insufficient to explain how the pathways for the principal olfactory axons subclasses are reorganized along the medio-lateral axis within the olfactory nerve. The spatial reorganization of the pathways may suggest the second mechanism that particular principal olfactory axon subclasses are selectively guided on the influence of their own targets located at specified positions within the olfactory bulb. In the trout olfactory projection the segregation of the principal olfactory axons occurs as they enter the olfactory bulb, suggesting an influence of the targets on the organization of the olfactory pathways (Riddle et al., 1993). The present findings that the segregation of the immunostainings for MAbA5 and MAbB2 in the olfactory nerve at stage 48 is not so clear as in the nerve at stage 55 (compare Figs. 5, 7) may indicate that the influence of the targets is a primary mechanism for the organization of the olfactory pathway, particularly at early stages of development.

Our current model for the organization of the principal olfactory projection in Xenopus tadpoles is shown in Figure 9. In early stages of development, the neuropilin-predominant and the plexin-predominant principal olfactory receptors send axons to their specified targets, probably via influences of the targets, and establish a spatial framework of the olfactory projections. The lately developed neuropilin-predominant and plexin-predominant receptors which differentiate at random positions within the principal olfactory epithelium send their axons preferentially along the preformed neuropilin-predominant or the plexin-predominant axons via a selective axon interaction, as has been proposed in developing insect nervous systems (Goodman et al., 1984; Raper et al., 1984). The model can easily explain how the stereotyped patterns of the principal olfactory pathways and projections are kept throughout continuous adding of new receptors during development. The present study indicates that the neuropilin-predominant and the plexin-predominant principal olfactory axon subclasses project to specified glomeruli in topographically related regions within the main olfactory bulb. The results, however, do not speak to the issue of whether the neuropilin and/or the plexin are directly involved in the interactions between growing olfactory axons and their targets to establish spatial patterns of the olfactory projections, since the neuropilin-predominant and the plexin-predominant axons have been segregated before they arrive at target regions.

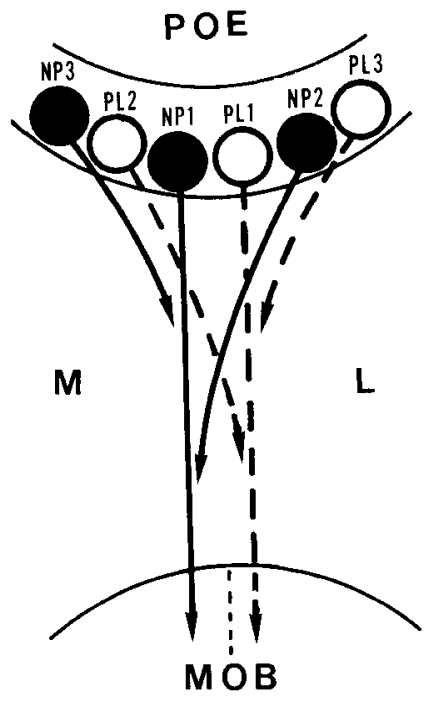

Figure 9. A schematic representation of the model for the organization of the olfactory projection. $N P I$ and $P L$ indicate neuropilin-predominant and plexin-predominant principal olfactory receptors $(P L)$ differentiated within the principal olfactory epithelium $(P O E)$, at early stages of development, respectively. Their axons arrive at appropriate positions within the main olfactory bulb $(M O B) . N P 2, N P 3$ and $P L 2, P L, 3$ indicate neuropilin-predominant and plexin-predominant receptors which differentiate at later stages of development, at random positions within the principal olfactory epithelium, respectively. Axons of these lately formed receptors choice appropriate preformed axons or axon bundles by virtue of their cell surface labels with the neuropilin or plexin, and then arrive at their correct termination sites within the main olfactory bulb. $M$, medial; $L$, lateral.

The findings that the axons with the more neuropilin project to the more medial glomeruli; vice versa, the axons with the more plexin to the more lateral glomeruli lead to speculation that the neuropilin and the plexin might serve as some forms of positional cue by which the spatial patterns of the principal olfactory projection are regulated.

Several cell surface molccules that express on restricted subsets of neurons and axons have been identified in developing insect nervous systems (Bastiani et al., 1987; Patel et al., 1987; Seaver et al., 1991; Nose et al., 1992), in the vertebrate somatosensory system (Dodd et al., 1984; Dodd and Jessell, 1985; Jessell and Dodd, 1985; Lawson et al., 1985; Regan et al., 1986; Dodd et al., 1988; Shimamura et al., 1992), and in the mammalian olfactory system (Allen and Akeson, 1985a,b; Schwob and Gottlieb, 1986, 1988; Mori, 1987). However, the contribution of these cell surface molecules to the formation of nerve fiber tracts and connections has still been circumstantial, except some molecules found in the insect in which genetic approaches are available (Bastiani et al., 1987; Elkins et al., 1990; Grenningloh et al., 1991). To test exact roles of the neuropilin and the plexin in the organization of the olfactory pathways and connections, further analyses such as the manipulation of the neuropilin and plexin expression in vivo are essential.

Finally, several analyses on vertebrate olfactory system have suggested that olfactory receptor subclasses which respond to different odors project to topographically specified glomeruli within the olfactory bulb (Skeen, 1977; Stewart et al., 1979; Doving et al., 1980; Lancet et al., 1982). Thus, it will be of interest to test whether the neuropilin-predominant and the plexin-predominant principal olfactory receptors are functionally different, by means of electrophysiological and pharmaco- 
logical approaches in combination with the MAbA5- and MAbB2-immunohistochemistry.

\section{References}

Allen WK, Akeson R (1985a) Identification of an olfactory receptor neuron subclass: cellular and molecular analysis during development. Dev Biol 109:393-401.

Allen WK, Akeson R (1985b) Identification of a cell surface glycoprotein family of olfactory receptor neurons with a monoclonal antibody. J Neurosci 5:284-296.

Astic L, Saucier D (1986) Anatomical mapping of the neuroepithelial projection to the olfactory bulb in the rat. Brain Res Bull 16:445454.

Astic L, Saucier D, Holley A (1987) Topographical relationships between olfactory receptor cells and glomerular foci in the rat olfactory bulb. Brain Res 424:144-152.

Bastiani MJ, Raper JA, Goodman CS (1984) Pathfinding by neuronal growth cones in grasshopper embryos. III. Selective affinity of $\mathbf{G}$ growth cone for the $P$ cells within the $A / P$ fascicle. J Neurosci 4:23112328.

Bastiani MJ, Harrelson AL, Snow PM, Goodman CS (1987) Expression of fasciclin I and II glycoproteins on subsets of axon pathways during neuronal development in the grasshopper. Cell 48:745-755.

Bixby JL, Pratt RS, Lilien J, Reichardt LF (1987) Neurite outgrowth on muscle cell surfaces involves extracellular matrix receptors as well as $\mathrm{Ca}^{2+}$-dependent and-independent cell adhesion molecules. Proc Natl Acad Sci USA 84:2555-2559.

Bixby JL, Lilien J, Reichardt LF (1988) Identification of the major proteins that promote neuronal process outgrowth on Schwann cells in vitro. J Cell Biol 107:353-361.

Burton PR (1990) Vomeronasal and olfactory nerves of adult and larval bullfrogs. II. Axon terminations and synaptic contacts in the accessory olfactory bulb. J Comp Neurol 292:624-637.

Burton PR, Coogan MM, Borror CA (1990) Vomeronasal and olfactory nerves of adult and larval bullfrogs. I. Axons and the distribution of their glomeruli. J Comp Neurol 292:614-623.

Cervello M, Lemmon V, Landreth G, Rutishauser U (1991) Phosphorylation-dependent regulation of axon fasciculation. Proc Natl Acad Sci USA 88:10548-10552.

Chitnis AB, Kuwada JY (1991) Elimination of a brain tract increases errors in pathfinding by follower growth cones in the zebrafish embryo. Neuron 7:277-285.

Constanzo RM, O'Connell RJ (1978) Spatially organized projections of hamster olfactory nerves. Brain Res 139:327-332.

Dodd J, Jessell TM (1985) Lactoseries carbohydrates specify subsets of dorsal root ganglion neurons projecting to the superficial dorsal horn of rat spinal cord. J Neurosci 5:3278-3294.

Dodd J, Jessell TM (1988) Axon guidance and the patterning of neuronal projections in vertebrates. Science 242:692-699.

Dodd J, Solter D, Jessell TM (1984) Monoclonal antibodies against carbohydrate differentiation antigens identify subsets of primary sensory neurons. Nature 314:469-472.

Dodd J, Morton SB, Karagogeos D, Yamamoto M, Jessell TM (1988) Spatial regulation of axonal glycoprotein expression on subsets of embryonic spinal neurons. Neuron 1:105-116.

Doherty P, Cohen J, Walsh FS (1990a) Neurite outgrowth in response to transfected N-CAM change during development and is modulated by polysialic acid. Neuron 5:209-219.

Doherty P, Fruns M, Seaton P, Dickson G, Barton CH, Sears TA, Walsh FS (1990b) A threshold effect of the major isoforms of N-CAM on neurite outgrowth. Nature 343:464-466.

Doherty P, Ashton SV, Moore SE, Walsh FS (1991) Morphoregulatory activities of NCAM and N-cadherin can be accounted for by $\mathrm{G}$ protein-dependent activation of $\mathrm{L}$ - and $\mathrm{N}$-type neuronal $\mathrm{Ca}^{2+}$ channels. Cell 67:21-33.

Doving KB, Selset R, Thommesen G (1980) Olfactory sensitivity to bile acids in salmonid fishes. Acta Physiol Scand 108:123-131.

Elkins T, Zinn K, McAllister L, Hoffmann FM, Goodman CS (1990) Genetic analysis of a Drosophila neural cell adhesion molecule: interaction of fasciclin I and Abelson tyrosine kinase mutations. Cell 60:565-575.

Fujisawa H, Ohtsuki T, Takagi S, Tsuji T (1989) An aberrant retinal pathway and visual centers in Xenopus tadpoles share a common cell surface molecule, A5 antigen. Dev Biol 135:231-240.
Fujisawa H, Takagi S, Hirata T (1990) Cell surface molecule A5: a putative involvement in retinal central connection. Neurosci Res [Suppl] 13:11-17.

Fujita SC, Mori K, Imamura K, Obata K (1985) Subclasses of olfactory receptor cells and their segregated central projections demonstrated by a monoclonal antibody. Brain Res 326:192-196.

Furley AJ, Morton SB, Manalo D, Karagogeos D, Dodd J, Jessell TM (1990) The axonal glycoprotein TAG-1 is an immunoglobulin superfamily member with neurite outgrowth-promoting activity. Cell 61:157-170.

Goodman CS, Shatz CJ (1993) Developmental mechanisms that generate precise patterns of neuronal connectivity. Cell $72 /$ Neuron 10[Suppl]:77-98.

Goodman CS, Bastiani MJ, Doe CQ, du Lac S, Helfand SL, Kuwada JY, Thomas JB (1984) Cell recognition during neuronal development. Science 225:1271-1279.

Grenningloh G, Rehm MJ, Goodman CS (1991) Genetic analysis of growth cone guidance in Drosophila: fasciclin II functions as a neuronal recognition molecule. Cell 67:45-57.

Hirata T, Takagi S, Fujisawa H (1993) The membrane protein A5, a putative neuronal recognition molecule, promotes neurite outgrowth. Neurosci Res 17:159-169.

Imamura K, Mori K, Fujita SC, Obata K (1985) Immunochemical identification of subgroups of vomeronasal nerve fibers and their segregated terminations in the accessory olfactory bulb. Brain Res 328:362-366.

Jessell TM, Dodd J (1985) Structure and expression of differentiation antigens on functional subclasses of primary sensory neurons. Philos Trans R Soc Lond [Biol] 308:271-281.

Key B, Giorgi PP (1986) Soybean agglutinin binding to the olfactory systems of the rat and mouse. Neurosci Lett 69:131-136.

Kuwada JY (1986) Cell recognition by neuronal growth cones in a simple vertebrate embryo. Science 233:740-746.

Laemmli UK (1970) Cleavage of structural proteins during the assembly of the head of bacteriophage T4. Nature 227:680-685.

Lancet D, Greer CA, Kauer JS, Shepherd GM (1982) Mapping of odor-related neuronal activity in the olfactory bulb by high-resolution 2-deoxyglucose autoradiography. Proc Natl Acad Sci USA 79:670674.

Land LJ (1973) Localized projections of olfactory nerves to rabbit olfactory bulb. Brain Res 63:153-166.

Land LJ, Shepherd GM (1974) Autoradiographic analysis of olfactory receptor projections in the rabbit. Brain Res 70:506-510.

Land LJ, Eager RP, Shepherd GM (1970) Olfactory nerve projections to the olfactory bulb in rabbits: demonstration by means of a simplified ammoniacal silver degeneration technique. Brain Res 23:250 254.

Lawson SN, Harper EI, Harper AA, Garson JA, Coakham HB, Randle BJ (1985) Monoclonal antibody 2C5: a marker for a subpopulation of small neurons in rat dorsal root ganglia. Neuroscience 6:365-374.

Lemmon V, Burden SM, Payne HR, Elmslie GL, Hlavin ML (1992) Neurite growth on different substrates: permissive versus instructive influences and the role of adhesive strength. J Neurosci 12:818-826.

Mori K (1987) Monoclonal antibodies (2C5 and 4C9) against lactoseries carbohydrates identify subsets of olfactory and vomeronasal receptor cells and their axons in the rabbit. Brain Res 408:215-221.

Mori K, Fujita SC, Imamura K, Obata K (1985) Immunohistochemical study of subclasses of olfactory nerve fibers and their projections to the olfactory bulb in the rabbit. J Comp Neurol 242:214-229.

Mori K, Imamura K, Fujita SC, Imamura K, Obata K (1987) Projections of two subclasses of vomeronasal nerve fibers to the accessory olfactory bulb in the rabbit. Neuroscience 20:259-278.

Neugebauer KM, Tomaselli KJ, Lilien J, Reichardt LF (1988) NCadherin, N-CAM, and integrins promote retinal neurite outgrowth on astrocytes in vitro. J Cell Biol 107:1177-1187.

Nieuwkoop PD, Faber J (1956) Normal table of Xenopus laevis (Daudin). Amsterdam: North-Holland.

Nose A, Mahajan VB, Goodman CS (1992) Connectin: a homophilic cell adhesion molecule expressed on a subset of muscles and the motoneurons that innervate them in Drosophila. Cell 70:553-567.

Ohta K, Takagi S, Asou H, Fujisawa H (1992) Involvement of neuronal cell surface molecule $B 2$ in the formation of retinal plexiform layers. Neuron 9:151-161.

Onoda N, Fujita SC (1988) Monoclonal antibody immunohistochemistry of adult rabbit olfactory structures. Neuroscience 26:993-1002. 
Patel NH, Snow PM, Goodman CS (1987) Characterization and cloning of fasciclin III: a glycoprotein expressed on a subset of neurons and axon pathways in Drosophila. Cell 48:975-988.

Pedersen PE, Jastreboff PJ, Stewart WB, Shepherd GM (1986) Mapping of an olfactory receptor population that projects to a specific region in the rat olfactory bulb. J Comp Neurol 250:93-108.

Raper JA, Bastiani MJ, Goodman CS (1984) Pathfinding by neuronal growth cones in grasshopper embryos. IV. The effects of ablating the $A$ and $P$ axons upon the behavior of the $G$ growth cone. $J$ Neurosci 4:2329-2345.

Regan LJ, Dodd J, Barondes SH, Jessell TM (1986) Selective expression of endogenous lactose-binding lectins and lactoseries glycoconjugates in subsets of rat sensory neurons. Proc Natl Acad Sci USA 83:2248-2252.

Riddle DR, Oakley B (1991) Evaluation of projection patterns in the primary olfactory system of rainbow trout. J Neurosci 11:3752-3762.

Riddle DR, Oakley B (1992) Immunocytochemical identification of primary olfactory afferents in rainbow trout. J Comp Neurol 324: 575-589.

Riddle DR, Wong LD, Oakley B (1993) Lectin identification of olfactory receptor neuron subclasses with segregated central projections. J Neurosci 13:3018-3033.

Saucier D, Astic L (1986) Analysis of the topographical organization of olfactory epithelium projections in the rat. Brain Res Bull 16:455462.

Scalia F (1976) Structure of the olfactory and accessory olfactory systems. In: Frog neurobiology (Llinas R, Precht W, eds), pp 213-233. New York: Springer.

Schwob JE, Gottlieb DI (1986) The primary olfactory projection has two chemically distinct zones. J Neurosci 6:3393-3404.

Schwob JE, Gottlieb DI (1988) Purification and characterization of an antigen that is spatially segregated in the primary olfactory projection. J Neurosci 8:3470-3480.

Seaver E, Karlstrom RO, Bastiani MJ (1991) The restricted spatial and temporal expression of a nervous-system-specific antigen involved in axon outgrowth during development of the grasshopper. Development 111:881-893.

Shimamura K, Takahashi T, Takeichi M (1992) E-cadherin expression in a particular subset of sensory neurons. Dev Biol 152:242-254.

Shinoda K, Shiotani Y, Osawa Y (1989) "Necklace olfactory glomeruli" form unique components of the rat primary olfactory system. J Comp Neurol 284:362-373.

Skcen LC (1977) Odor-induced patterns of deoxyglucose consumption in the olfactory bulb of the tree shrew, Tupaia glis. Brain Res 124: 147-153.

Sonderegger P, Rathjen FG (1992) Regulation of axonal growth in the vertebrate nervous system by interactions between glycoproteins belonging to two subgroups of the immunoglobulin superfamily. J Cell Biol 119:1387-1394.

Stewart WB, Kauer JS, Shepherd GM (1979) Functional organization of rat olfactory bulb analyzed by the 2-deoxyglucose method. J Comp Neurol 185:715-734.

Takagi S, Tsuji T, Amagai T, Takamatu T, Fujisawa H (1987) Specific cell surface labels in the visual centers of Xenopus laevis tadpole identified using monoclonal antibodies. Dev Biol 122:90-100.

Takagi S, Hirata T, Agata K, Mochii M, Eguchi G, Fujisawa H (1991) The A5 antigen, a candidate for the neuronal recognition molecule, has homologies to complement components and coagulation factors. Neuron 7:295-307.

Towbin H, Staehelin T, Gordon J (1979) Electrophoretic transfer of proteins from acrylamide gels to nitrocellulose sheets: procedure and some applications. Proc Natl Acad Sci USA 76:4350-4354. 